\title{
Development of formative research in teaching processes to enhance the professional profile of undergraduate students
}

\author{
Christian Pavón, Mg. ${ }^{1}$, Margarita Naranjo, Mg. ${ }^{1}$, and Gabriela Carrillo, BA ${ }^{1}$ \\ ${ }^{1}$ University of Guayaquil, Ecuador, christian.pavonb@ug.edu.ec, margarita.naranjov@ug.edu.ec, gabriela.carrillol@ug.edu.ec
}

\begin{abstract}
The article presents a case study of the elaboration process and the results obtained in a seed research project developed and executed during 12 months by 6 undergraduate students of the University of Guayaquil together with a tutor using the method based on project-based learning. In addition, a final interview was conducted with the participants and discourse analysis was used to examine personal and academic achievements. The results were the development of oral and written planning and communication skills in the participating students, as well as some publications in congresses and refereed journals.
\end{abstract}

Keywords-- Project-based learning, project design, seed projects, higher education.

\section{INTRODUCTION}

Research seedbeds arise in different innovation centers and universities so that young people who are still undergrads, take their first steps with themes and / or projects. This in turn is used as a learning strategy, based on the principle of learning by doing, where problematic situations proposed in projects are discussed, socialized and analyzed, around themes related to the object of study of the academic programs offered by HEIs (Institutions in Higher Education). At the same time it allows the incorporation of groups of students that work with pedagogical and investigative purposes, oriented and supported by teachers, using methodologies, models and pedagogical strategies of investigation. Thus, creating the space where students and teachers of different disciplines converge for the purpose of searching an integral formation.

This activity is promoted by HEIs (Institutions of Higher Education) with the objective that teachers and students make known their research initiatives and these, in turn, determine the bases in their research, allowing them to achieve critical, creative and of argumentation in the task of the learning process. Similarly it is to move the process of formal education, towards new trends, which is conceived spaces for participation in the real environment that lead to finding solutions to problems related to education.

The research proposal projected by university academics aims to meet the training needs of students, keeping correspondence with their academic level [1]. In the constitution of the Republic of Ecuador, in its article 350. It tells us that "The Higher Education System has the purpose of academic and professional training with a scientific and humanistic vision; scientific and technological research; innovation, promotion, development and dissemination of knowledge and cultures; the construction of solutions for the country's problems, in relation to the objectives of the development regime."

The objective of the University of Guayaquil is to promote the development, consolidation and projection of research for the generation of science, art, culture, technology and innovation. Another of its objectives is the solution of the problems that allow transforming our Society in Regional, National and International spheres. Those that are visible in its seven lines of research: Culture, democracy and society; Sovereignty, rights and technologies in territorial planning and construction environment; Local development and sustainable and sustainable socio-economic entrepreneurship; Human, animal and environmental health; Biotechnological development, conservation and sustainable use of natural resources and adaptation to climate change; Basic sciences, bio-knowledge and industrial development; and, Inclusive and inclusive educational strategies. The same that through its 18 academic units are grouped by fields of knowledge: Health and Wellbeing (Medical Sciences, Chemical Sciences, Physical Education, Sports and Recreation, and Dentistry); Business Administration (Administrative Sciences); Education Arts and Humanities (Philosophy, Literature and Education Sciences); Industrial Engineering and Construction (Architecture and Urbanism, Industrial Engineering, Mathematical and Physical Sciences, and Chemical Engineering); Social Sciences, Journalism and Information (Economic Sciences, Psychological Sciences, Jurisprudence, Social and Political Sciences, and Social Communication); and, Natural Sciences, Agriculture and Veterinary (Agricultural Sciences, Natural Sciences, Sciences for Development and Veterinary Medicine and Zootechnics). The Faculty of Philosophy, Literature and Education Sciences responds to the search for solutions to current problems by generating integrative and inclusive educational strategies concerning areas of influence 5 and 8 at the national level according to the national development plan.

These seed projects have a financing of \$1500.00 USD, with a 12-month execution time. These proposals go through an evaluation committee for its approval, considering the Department of the Research Directorate as the regulatory body which will oversee the projects have the endorsement of scientific merit by the Scientific Committee of the proposing faculty. Through these calls, participation is stimulated for the presentation of proposals that arise from classroom environments that contribute to the search for solutions in 
educational environments and endowment of skills and investigative abilities in subjects [2].

This function of proposing research activities from the aulic spaces attributes to the strategic work of UNESCO that is to be an international laboratory of ideas, capable of rethinking education in a changing world, to serve as a platform for reflection and to guide the global debate, inspiring new approaches and guiding the development of educational policies globally. In this context, various modalities of action research, self-evaluation, systematization and reflection on pedagogical practices have been reassessed as essential strategies to nourish and sustain educational innovations, constituting at the same time as professional training tools in service. To implement good practices it is necessary to reflect on the scope of some improvements undertaken in the classroom or in the management of institutions [3].

The University of Guayaquil within its curricular structure hosts the Ecological model which has components of human and citizen principles and values. Among the factors enter the society that aspires to build and transform, the citizens and intercultural subjects that are going to be formed, the knowledge that is organized for the resolution of problems: Methodological convergence, the learnings based on the practice of action research, Strategies, environments and contexts of learning, social management of knowledge; and, functions and profile of the professor-researcher.

This model allows us to understand the educational practice as a set of relationships, in which diversity and difference coexist, and whose dynamic of social learning of culture generates the tensions of human interactions. These are debated and interdependence, between passion and information, open "niches" that strengthen the constitution of the subjects and direct the search for harmony, from a compromise between ethics and epistemology, science and culture, knowledge and wisdom [4].

The pedagogical model is articulated in the knowledge organization process, the integrating chair, the apprentice's experience and its condition as producer-manager of researchintervention projects and the tutorial processes that allow accompanying and subjectively to the student in the trajectory of his training praxis. Praxis, based on the dynamic experience-theoretical reflexivity of the practice of theory experimentation [5] with systematic and permanent feedback dynamics, favors students' capacities in their being (think, do, communicate) [6] and in his will (Project of life social undertakings of knowledge, values, attitudes, abilities and emotions. [7] Through its systematic application, we ensure the development of the habit that guarantees the growth of the subject.

The subject learns by being a protagonist in the appropriation of narratives, the ability to elaborate representations and models of abstract thinking, with the ability to analyze and demonstrate their knowledge in spaces of reality, demonstrating their knowledge and know-how with a preponderant role when they become responsible citizen with its surroundings, preparing to transcend in all areas of its life [4].

Therefore, this curriculum enables the necessary interactions to generate professional praxis and make research the basis for the articulation of knowledge integration projects. These are the basis of the dynamics of organization of knowledge and application of them in successive approaches to a changing reality, with real problems that must be resolved to the extent that the formation of practical thinking is promoted. This implies effective rationality and learning communities that act as strategic intelligence collectives that generate knowledge alternatives for the solution of educational problems.

Action research is the backbone of the curricular organization. The trajectory in which the student enters part of the participative observation for the realization of the descriptive diagnosis of the educational reality, is done determining the possible prototypical and specific problems. This is done with the analysis and interpretation of the contexts, processes, phenomena and situations with the contribution of knowledge, knowledge and experiences that configure the theoretical-methodological constructs. These are the basis of the construction of the design and planning of prevention and resolution proposals that are developed from negotiations of meaning with the learning communities, who will be part of the processes of evaluation, systematization and feedback of the praxis. In this way, the self-echo organization of the actors and institutions is promoted, that is, processes of strengthening of autonomy, the globality of ecological thinking-always relational and integrating and the organization that emerges from creativity and tension between the order and disorder of reality. Only these conditions will allow to assume the complexity and uncertainty of knowledge according to the tensions demanded by the social environment. The educational institutions are committed to respond to these problems and social tensions by generating research that allows transformations, changes and constructions that are oriented to develop the improvement and therefore the quality of the knowledge organization processes and their learning, which involve their generation and resolutions of socio-educational problems.

For these purposes, it is incorporated in the ABP (Project Based Learning) method. This is based on the formulation of a project conducted by the teacher as a facilitator with the participation of their students in the classroom. Groups are created and propitiate the necessary tools to solve it, and in the search for the solution develop procedural cognitive skills that will allow the subject to perform actions that encompass skills, strategies and processes that involve a sequence of actions or operations to be performed in an orderly manner to reach the goal.

This methodology of PBL, allows the student to travel (in an abbreviated manner) along paths similar to those that the

$1^{\text {th }}$ LACCEI International Multi-Conference for Engineering, Education, and Technology: "Innovation in Education and Inclusion", 19-21 July 2018, Lima, United States. 
scientist traveled to reach their conclusions. In this transit the subject not only appropriates knowledge, but the logic of the science in question in the solution of a given problem; for this, the teacher does not provide the knowledge already manufactured, but focuses on getting the student to reflect the contradictions of the phenomenon studied. In the form of a problem, it creates a problematic situation, in order that the student feels motivated to solve it and appropriates the knowledge and methods of scientific thought [8].

Project-Based Learning (PBL) is a student-centered teaching methodology that seeks to integrate theory and practice by bringing the academic context to the socio-labor context [9]. It is necessary to have the following steps: Study of context, understanding of the problem, search for alternatives, selection of the best alternative and execution scenarios. This methodology allows the integration of knowledge in a dynamic way in the teaching process. These lead to the development of scientific skills for the development of scientific thinking considering this vitally important for the subject to perform in the real world located by science and technology. This is divided into a pre-theoretical period which allows him to distinguish explanations and descriptions of the study phenomenon; the second the restricted theorist makes explanations going to the theoretical concepts and to the resolutions between logically interconnected laws; and the third holistic theory comprises general explanations and holistic general explanations which is characterized by the ability of the individual to establish relationships between the various general disciplinary theories being able to articulate procedures that validate empirical observations and can predict behaviors or results as a consequence of your prediction. In the curricular guidelines related to science, technology and education, which make sense through the relationship that can be established with the teaching process and the evaluation process that takes place in learning environments.

This process was born from an academic research idea with the participation of a teacher and students, as active subjects in the development of a Seed project, as specified in Fig. 1, which includes the methodology used for its application.

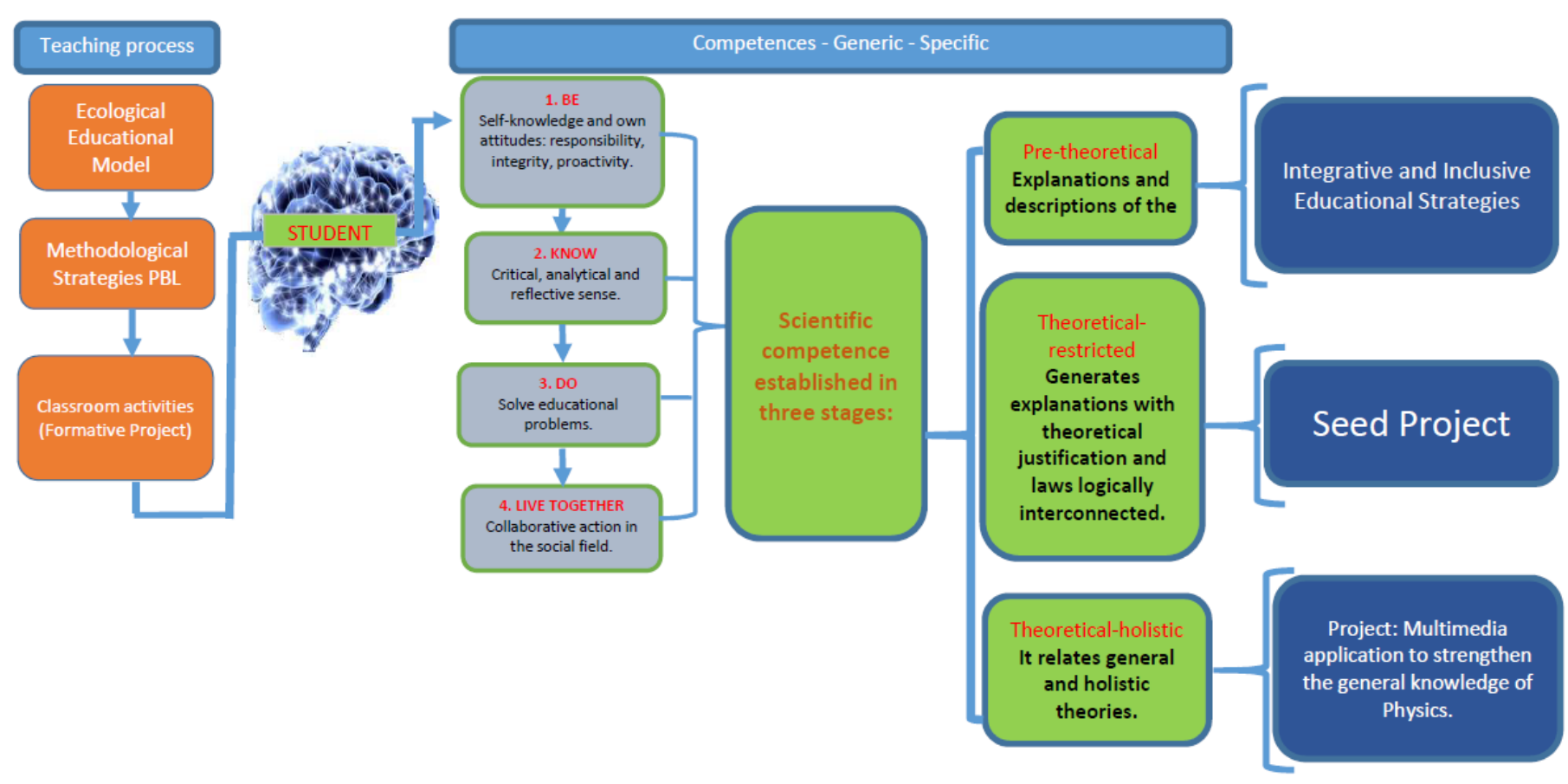

Fig. 1 Teaching process, competences and results of the implemented project.

16 $^{\text {th }}$ LACCEI International Multi-Conference for Engineering, Education, and Technology: "Innovation in Education and Inclusion", 19-21 July 2018, Lima, United States. 


\section{METHODOLOGY}

This study involved six students, two women and four men between 19 and 22 years of age, from an Ecuadorian university, along with a tutor.

For the elaboration of the seed project, Project-Based Learning was used as a method, in which the students had to plan, implement and evaluate a project that has an impact that goes beyond the classroom $[10,11,12]$.

In addition, the Learning Based on Scientific Research was used, with support in the didactic "early incorporation to scientific research", which turns out to be an essential tool to contribute in the teaching-learning process. This innovative way of approaching knowledge provides the student with the methodological elements with which a scientific spirit will be promoted that will allow him, as a starting point, to reflect on the current conditions of the environment that surrounds him, then detect the problems related to his area knowledge and creatively seek appropriate solutions finally perform dissemination of the results [13].

These phases are included in five activities that will make the research process feasible, as shown in Fig. 1. The first consists of guiding students to analyze the context within which the problem is located, both locally and globally, to understand it in its entirety. The second being to define the characteristics of the problem that is presented to them; that is to say, that they identify their specificity and analyze it in depth. The third one is to establish alternatives of logical solutions of the problem generating debate and with it "brainstorm" on possible alternatives of solution. Then analyze each alternative valuing the costs and benefits. The fourth is oriented to the subject to compare the different alternatives to solve the problem to determine alternatives that go from the simple to the complex in order that they represent greater benefits and lower costs in the short or long term and finally we have the fifth step which allows to apply the solution of a real or simulated scenario in an effective way.

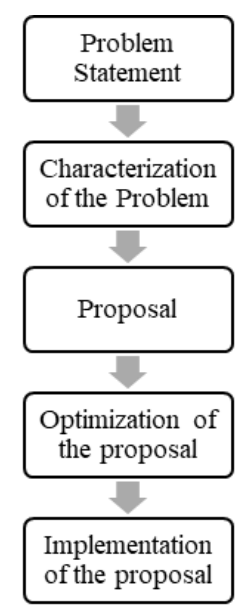

Fig. 2 Stages of Learning Based on Scientific Research.
Finally, a discourse analysis was carried out, through interviews carried out with the project participants to examine personal and academic achievements.

\section{RESULTS}

As a first result, the seed project developed in class [14] was approved by the scientific committee of the university. For this, among the participating students, a representative was chosen to carry out a support of the seed project in a session of the research department of the university. The student who made the exhibition was also designated as student coordinator of the project.

During the development of the project, the student coordinator of the project participated as co-author and speaker in two papers presented at national and international conferences [14] [15].

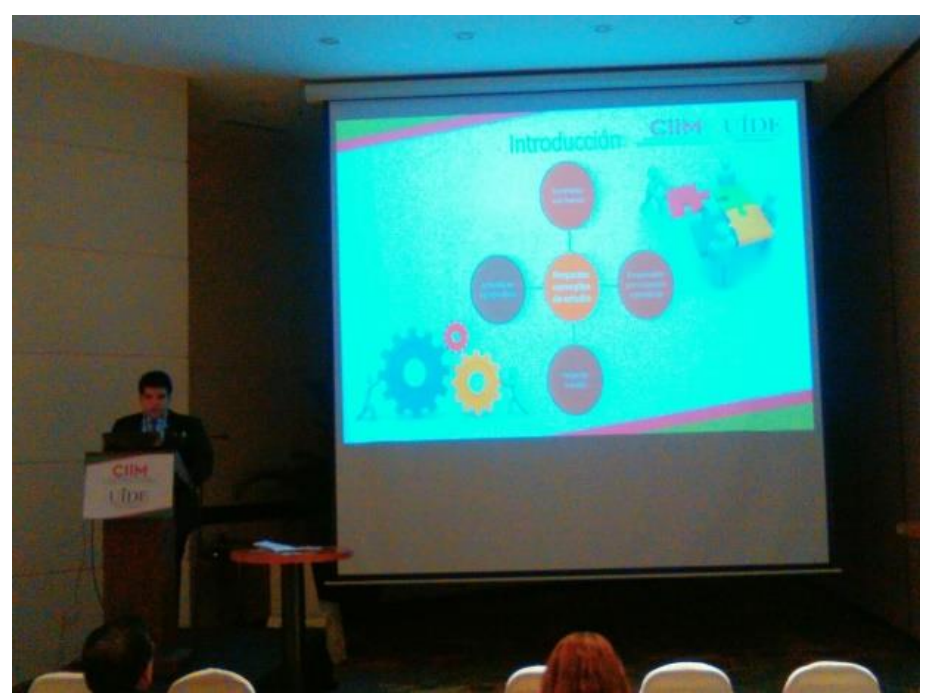

Fig. 3 Student coordinator making a presentation.

Finally, an interview was held with the participants of the seedbed. They were asked questions related to the development of the project, the skills related to their academic or daily activity and their possible participation in future research projects.

Based on the analysis of the answers given by the participants during the interviews, the following soft skills [16] were determined: 
TABLE I

EXCERPT FROM INTERVIEWS WITH PARTICIPATING STUDENTS

\begin{tabular}{|c|c|}
\hline Skills & Extract of the interview \\
\hline $\begin{array}{l}\text { Attention and } \\
\text { listening capacity }\end{array}$ & $\begin{array}{l}\text { S1: "teamwork improved notoriously because by } \\
\text { gaining a better understanding of the subject it was } \\
\text { possible to optimize time and contributed with what } \\
\text { was required". }\end{array}$ \\
\hline Self-regulation & $\begin{array}{l}\text { S2: "to be more meticulous, since it was an } \\
\text { essential point to develop the project and being in } \\
\text { suitable conditions for those directed, both at the } \\
\text { level of organization and research was the most } \\
\text { detailed to get the development of the project". }\end{array}$ \\
\hline Curiosity & $\begin{array}{l}\text { S3: "changed my way of looking at the research } \\
\text { field since I was more curious and interested in } \\
\text { looking for some sources of different texts in } \\
\text { physics and on the web". }\end{array}$ \\
\hline $\begin{array}{l}\text { Personal and social } \\
\text { responsibility }\end{array}$ & $\begin{array}{l}\text { S2: "Being present in the research field provides a } \\
\text { high reinforcement to any prior knowledge. It is } \\
\text { essential to be in constant research for the } \\
\text { development of society, which these projects are } \\
\text { effective whatever the area of development". } \\
\text { S4: "I would like to continue participating in this } \\
\text { type of projects to be able to improve all the } \\
\text { information with new knowledge and tools that } \\
\text { improve the teaching - learning process and } \\
\text { achieving a well-educated society". }\end{array}$ \\
\hline Intrinsic motivation & $\begin{array}{l}\text { S5: "It has motivated me to get involved in this } \\
\text { kind of projects, because it tests my learning ability } \\
\text { and my teaching methodology". }\end{array}$ \\
\hline Divergent logic & $\begin{array}{l}\text { S6: "I think I developed my creativity; at the time } \\
\text { of asking the questions I looked for a simple, } \\
\text { simplified and entertaining way to illustrate them, } \\
\text { supporting me even with elaborate graphics". }\end{array}$ \\
\hline Continuous learning & $\begin{array}{l}\text { S4: "It allowed me to develop new skills for the } \\
\text { search and organization of information, develop it } \\
\text { and generate ideas of support for the project". } \\
\text { S5: "In this project a thorough and meticulous } \\
\text { research was necessary: read and analyze each of } \\
\text { the topics carefully". }\end{array}$ \\
\hline $\begin{array}{l}\text { Capacity for synthesis } \\
\text { and argumentation }\end{array}$ & $\begin{array}{l}\text { S3: "The skill that I noticed I gained was the } \\
\text { analysis and development of the information, } \\
\text { allowing me to increase my knowledge and } \\
\text { optimize the project, collecting useful information } \\
\text { and developing questions". } \\
\text { S1: "I was able to improve the ability to analyze } \\
\text { each exercise before solving it, seeking to arrive at } \\
\text { the result in an agile and secure way". }\end{array}$ \\
\hline
\end{tabular}

\section{CONCLUSIONS}

The high motivation of the students to learn through the accomplishment of projects of collaborative form and making use of diverse technological tools goes of the hand of a very positive self-perception of the obtained learning. The students consider interesting what they have learned and would like to continue learning about the subject. The motivation and the academic success derive from the fact of proposing activities adapted to the interests of the students and that they assume responsibilities in the tasks, feeling protagonists [17].
The students confirm a high level of commitment, considering that they have read and concentrated a lot during the proposed activities, as well as they have created and shared information. In all these aspects coherence has been found between the opinion of the students and the teacher responsible for the development of the seed project.

The results obtained reiterate, not only the importance of students' motivation to achieve significant learning, but also the need for good planning and organization of tasks in projects.

The conclusions of other studies indicate that the design of projects requires an effort of planning and monitoring since the fact of creating a common space does not ensure either communication or collaboration. For this reason, it is important to consider the forms of monitoring and evaluation of the process very well.

In most of the research carried out on the subject [18] [19] the important role of the teacher for the good development of project-based learning has been highlighted, both to the relevant, authentic and motivating activities, leaving room for responsibility of students to make proposals as the process progresses, such as to guide in the completion of tasks, mark guidelines and phases, help students become aware of the process to be followed and the results achieved [20].

Finally, we hope that this work contributes to the consolidation of project-based learning as an alternative to traditional teaching strategies, emphasizing the need to find new evaluation formulas in these methodological contexts that allow evaluating not only the results or products generated in the development of the project but also the processes, both external and internal, carried out by the working groups. For this, the participant observation by the teachers during the school activity can have a great relevance but they must also have valid and reliable instruments that allow them to know the point of view of their students in a rigorous way, for which they have contributed the "PEL evaluation scale by the students" as a very useful instrument in the professional performance of teachers who incorporate methodologies of project-based learning in their teaching practice.

\section{REFERENCES}

[1] Asamblea Constituyente, Constitución del Ecuador, 2008.

[2] Universidad de Guayaquil, Reglamento provisional para el funcionamiento de semilleros de investigación de la UG, 2015.

[3] Unesco, «Innovación Educativa,» de Herramientas de apoyo para el trabajo docente, Lima, Unesco: Perú, 2016, pp. 13-14.

[4] E. Larrea y M. Montalvan, Modelo Educativo Ecológico de la Universidad de Guayaquil, Guayaquil, Guayas: Eduquil, 2016.

[5] F. Korthagen, «La práctica, la teoría y la persona en la formación del profesorado,» Revista Interuniversitaria de Formación del Profesorado, vol. 64, no 24, pp. 83-101, 2010.

[6] C. Correa y J. Rúa, El aprendizaje basado en problemas en la educación superior, Medellín: Universidad de Medellín, Sello Editorial, 2009.

[7] Á. Pérez, Educarse en la era digital, Madrid: Ediciones Morata, S.L., 2012.

$16^{\text {th }}$ LACCEI International Multi-Conference for Engineering, Education, and Technology: "Innovation in Education and Inclusion", 19-21 July 2018, Lima, United States. 
[8] M. Naranjo, Empleo de técnicas ABP como estrategia didáctica en la enseñanza de aspectos ambientales y actividades productivas de la carrera de Desarrollo Comunitario Ambiental de la Universidad de Guayaquil, Guayaquil: Universidad de Guayaquil, 2015.

[9] Á. Simó, S. Ferreira y P. Ortuño, «Workshops interdisciplinares: implementación de metodologías de aprendizaje basado en proyectos y cooperativo,» Opción, vol. 32, n 10, pp. 752-772, 2016.

[10] W. Blank, «Authentic instruction,» de Promising practices for connecting high school to the real world, Tampa, FL, University of South Florida, 1997, pp. 15-21.

[11] S. Harwell, «Project-based learning,» de Promising practices for connecting high school to the real world, Tampa, FL, University of South Florida, 1997, pp. 23-28.

[12] L. Galeana, «Aprendizaje basado en proyectos,» Revista Digital: Investigación en Educación a Distancia, 2006.

[13] L. Galán, «Aprendizaje Basado en la Investigación Científica (ABIC), en los estudiantes de L.C.P. del CUCIÉNEGA de la Universidad de Guadalajara,» Opción, vol. 32, nº 13, pp. 514-539, 19 Septiembre 2016.

[14] C. Pavón, J. Encalada y K. Matutte, «Página web para fortalecer el conocimiento general de la Física: un ejemplo de proyecto semillero,» INNOVA Research Journal, vol. 1, nº 12, pp. 23-28, 2016.

[15] C. Pavon, J. Encalada, K. Matute y J. Rodríguez, «Web page to improve feedback in the teaching of Physics in baccalaureate: partial results of a research seed project,» de 15th LACCEI International Multi-Conference for Engineering, Education, and Technology: "Global Partnerships for Development and Engineering Education”, Boca Raton, 2017.

[16] B. Schulz, «The Importance of Soft Skills: Education beyond academic knowledge,» Journal of Language and Communication, pp. 146-154, 2008.

[17] J. Krajcik y P. Blumenfeld, Project-based learning, Cambridge: Cambridge University Press, 2006.

[18] K. Brundiers y A. Wiek, «Do we teach what we preach? An international comparative appraisal of problem- and project-based learning courses in sustainability,» Sustainability, vol. 5, n 4, pp. 1725-1746, 2013.

[19] J. David, «What research says about project-based learning,» Educational Leadership, vol. 65, p. 80-82, 2008.

[20] I. García, B. Gros y I. Noguera, «La relación entre las prestaciones tecnológicas y el diseño de las actividades de aprendizaje para la construcción colaborativa del conocimiento,» Cultura y Educación, vol. 22, n 4, pp. 395-418, 2010.

16 $^{\text {th }}$ LACCEI International Multi-Conference for Engineering, Education, and Technology: "Innovation in Education and Inclusion", 19-21 July 2018, Lima, United States. 